\title{
Producción agrícola y organización política en las sociedades prehispánicas del Alto Magdalena
}

\author{
Agricultural Production and Political Organization \\ in Prehispanic Societies from Alto Magdalena
}

\section{Carlos Augusto Sánchez}

Departamento de Antropología, Universidad Nacional de Colombia casanchez@unal.edu.co

\section{RESUMEN}

El propósito de la arqueología debe ser explicar los hechos sociales del pasado y las razones de sus manifestaciones culturales con el fin de contribuir a propiciar un futuro menos aciago para el ser humano. En consecuencia, para producir conocimiento socialmente útil, es preciso esforzarnos en desentrañar los fundamentos de las instituciones objeto de la reproducción, con frecuencia enmascaradas como dramas sacros. En el caso del Alto Magdalena, durante el periodo Clásico Regional (1-900 d. C.), las élites en ciernes recurrieron a la sacralización de los ancestros, amparadas en un sistema de relaciones sociales pautado por el parentesco, con el propósito de fortalecer y garantizar la permanencia de la sociedad tributaria cacical.

Palabras clave: sociedad comunal, trabajo excedente, parentesco, agricultura intensiva.

\section{ABSTRACT}

The purpose of archaeology should be to explain the social phenomena of the past and the reasons behind their cultural expressions, in order to contribute to promoting a less ominous future for humankind. Consequently, to produce socially useful knowledge we must strive to unravel the foundations of the institutions of social reproduction, often masquerading as sacred drama. In the case of the Alto Magdalena during the Regional Classic period (AD 1-900), emerging elites resorted to the sacredness of the ancestors, protected by a system of social relationships based on kinship, in order to strengthen and ensure the permanence of a tributary chiefly society.

Keywords: communal society, surplus labor, kinship, intensive farming. 


\section{Introducción}

El estudio de la producción agrícola como categoría económica es un asunto de importancia capital para la comprensión de las sociedades de la historia prehispánica; en primera instancia, porque su práctica entraña relaciones sociales definidas entre los miembros de las comunidades comprometidas; en segundo lugar, porque las modalidades de la producción obedecen a disposiciones sociales que justifican y prescriben las formas de las organizaciones políticas en la sociedad, y, en tercer lugar, porque la producción de los recursos críticos (producción cuyo control y provecho, a la postre, se convierte en el factor central de la disputa social) tiene como fin fundamental solventar las necesidades indispensables para la vida y la reproducción social.

Desentrañar los fundamentos de las instituciones y de las representaciones que de ellas se hacen los miembros de una sociedad solo es posible si se consideran los procesos de producción, en primera instancia, de los recursos vitales para la vida y, consustancial a ello, de los mecanismos que reglamentan esos procesos. En consecuencia, es necesario aceptar que la economía y la política son factores inherentes a la vida social; la primera se refiere a la producción social de los recursos (materiales e inmateriales) y la segunda, a la administración, a la tutela de esa producción para lograr la reproducción de la estructura social en cuestión. Así, es en la vida cotidiana y en la producción de los recursos necesarios para solventar las necesidades en donde se establecen y caracterizan las relaciones sociales, cuya materialización corresponde al ámbito que la antropología denomina cultura.

Pero ¿cómo se materializan las relaciones sociales? Históricamente, en primera instancia, mediante la definición y consolidación de los sistemas de parentesco. Así, las entidades que consideramos, es decir, las comunidades de nuestra realidad arqueológica, están constituidas por grupos de parentesco que, al precisar el acceso a la tierra y, en ella, la obtención y producción de los bienes indispensables, establecen su dirección y control. En las sociedades sin Estado, los sistemas de parentesco pautan las relaciones sociales o, mejor, regulan las relaciones de producción. De hecho, los sistemas de parentesco, al ser entidades cerradas de relaciones sociales, generan grupos jerárquicos en los procesos de producción; establecen relaciones diferenciales que someten a los individuos y sus familias. Hace ya bastante tiempo lo señaló Godelier (2000), uno de los mayores conocedores del tema:

[...] las relaciones de parentesco constituyen los soportes del proceso de apropiación y de uso de la tierra o de los títulos, de estatus; en resumen, 
de realidades tanto tangibles como intangibles, que se presentan ante los actores sociales como algo esencial para la reproducción de sí mismos y de su sociedad. (109)

Esto no quiere decir que el parentesco prescriba la dirección política y que esta intervenga en forma rigurosa y permanente en los asuntos económicos y sociales; solo se trata de advertir que el parentesco determina derechos de dominio sobre territorios y sus recursos, y que para mantener la cohesión de la comunidad, coordinar el movimiento de recursos y regular la interacción entre individuos, unidades domésticas y comunidades, es necesaria la presencia de una institución eficaz.

La obtención o la producción de recursos, de bienes, tiene como finalidad solventar las necesidades individuales y colectivas, siempre diversas y en constante transformación. Estas necesidades son de tres tipos: unas, las esenciales, se caracterizan por su trascendencia para la sobrevivencia como seres biológicos, v. gr., alimento, vestuario, combustible, refugio e interdependencia social; otras necesidades, las más numerosas, son estrictamente de índole cultural, y resultan del vivir en conglomerados sociales definidos y hacer parte de ellos (clases sociales, grupos étnicos, credos religiosos, asociaciones profesionales o de solidaridad), v. gr., educación, tipos de vivienda, esparcimiento, pautas alimenticias, modas, gustos musicales, distintivos comunales; en tercer lugar, algunas necesidades biológicas y culturales adquieren mayores proporciones y alto valor social, entre ellas, alimentos exóticos, vestuarios suntuosos, viviendas ostentosas, recipientes en materiales escasos, tumbas de estructuras sobresalientes.

Por supuesto, para suplir esas necesidades es preciso disponer de materiales suministrados por la naturaleza que, al ser aplicado sobre ellos el trabajo humano, se convierten en productos y bienes. Precisamente, el conjunto de las actividades humanas en procura de la solución de las necesidades y en pos de la reproducción de las condiciones de existencia ${ }^{1}$ es lo que se denomina economía. Pero los procesos de producción no son hechos armónicos; por el contrario, ocurren en medio de profundas contradicciones y conflictos debidos a la participación técnica de los individuos en los procesos de trabajo, al acceso diferencial a

1 Grosso modo, se trata de generar conocimiento, tecnología, dirigir y controlar la producción de los bienes materiales y a los agentes que intervienen en esta; reproducir la fuerza de trabajo tanto en su forma física como en su adiestramiento, y fortalecer las ideas, los valores y las aspiraciones que afianzan las relaciones entre los individuos y entre las comunidades. 
los elementos y factores que intervienen en la producción ${ }^{2}$, y a los resultados del trabajo realizado (distribución y consumo), condiciones que implican necesariamente también relaciones sociales diferenciales.

Pero ¿cómo lograr que la producción efectivamente responda a las necesidades sociales y permita la reproducción de la estructura social? O de otro modo, ¿cómo se garantiza la organización del trabajo, se controlan los medios de producción y la distribución de los recursos y bienes producidos? Pues bien, esto solo es posible mediante la instauración de normas de comportamiento, derechos y deberes, e instituciones reguladoras del sistema productivo. Así pues, la función de la política es reglamentar, pautar y articular las relaciones sociales que se generan por la vida en común y en los procesos de producción de los recursos; en consecuencia, la política, aunque se halle maquillada, resulta ser, en última instancia, el ambiente sobre el que se cimienta el liderazgo, la jefatura en las comunidades.

Ahora bien, durante un extenso lapso de la historia del desarrollo social, la actividad política, y las instituciones creadas para que ella efectivamente funcionara, no requirió la presencia de actores permanentes encargados de su dirección, y las instituciones que asumían la regulación y materialización generalmente estaban enmascaradas, pautadas por el sistema de parentesco o la religión.

De lo anterior se concluye que las relaciones sociales, la economía, la política y los mecanismos que las justifican suceden al unísono; son interdependientes, aunque se hallan en permanente transformación, dado el aumento constante de las necesidades y de las estrategias para solventarlas.

Como investigadores de los asuntos de la producción y de la política en las sociedades de la historia antigua, nuestra misión consiste, en primera instancia, en analizar en forma concienzuda la calidad de las relaciones sociales y de las normas que gobiernan la vida social, tanto las obvias como las enmascaradas, que se gestan y manifiestan entre los individuos y grupos en los procesos de producción. Este es un principio que no se puede eludir, pues no es posible lograr explicaciones sensatas sobre los hechos del pasado (¡o del presente!) con base en las apariencias, en las escenificaciones dramáticas de esas relaciones. En segundo

2 Al conjunto de elementos y factores que se precisan para la producción lo denomina el marxismo medios de producción; comprende los objetos de trabajo, que corresponden al material sobre el que se aplica fuerza de trabajo (v. gr., la tierra de labranza para el agricultor); los medios de trabajo, que son los instrumentos, las habilidades, el conocimiento y las locaciones en que se lleva a cabo un proceso de trabajo (en el caso agrícola, respectivamente, el arado, la siembra en bancadas, la parcela), y la fuerza de trabajo, que se refiere al trabajo físico humano implementado e indispensable para que los dos factores anteriores realmente operen. 
lugar, es necesario considerar que las modalidades de la producción, aun cuando aparenten divergencias, son siempre y necesariamente compatibles con la formación económico-social dominante. Por lo tanto, para una comprensión cabal de cómo opera un sistema económico y qué es indispensable para que funcione en forma efectiva, es necesario saber cómo se produce y, una vez conocido este aspecto trascendental, es preciso saber cómo se distribuye lo producido.

La omisión de las anteriores premisas ha conducido a la levedad de las divagaciones y explicaciones dominantes sobre la naturaleza de las sociedades y expresiones culturales durante la historia prehispánica en el sur del Alto Magdalena. Por esa razón emprendemos este ejercicio teórico-metodológico de contrastación con los datos empíricos recabados en el marco de varios y prolongados proyectos de investigación realizados en el territorio del actual municipio de Isnos.

\section{El área de estudio}

El sur del Alto Magdalena, asiento de la llamada “cultura de San Agustín”, es una amplia región correspondiente a las cabeceras del río Magdalena, que discurre por el amplio valle que paulatinamente se abre hacia el norte desde el vértice que forman las cordilleras Central y Oriental; comprende básicamente el sur del actual departamento del Huila, en el sur de Colombia (figura 1). La variante altitudinal comprende desde el piso térmico cálido en la latitud del municipio de Tesalia, sobre la cota de $600 \mathrm{~m} \mathrm{s.} \mathrm{n.} \mathrm{m.}{ }^{3}$, hasta el piso térmico frío, sobre las cimas de las dos cordilleras (algo más de $3.000 \mathrm{~m} \mathrm{s.} \mathrm{n.} \mathrm{m.,} \mathrm{en} \mathrm{la} \mathrm{Central),} \mathrm{desde} \mathrm{las} \mathrm{cuales}$ discurren numerosos ríos y quebradas que depositan sus aguas en el río Magdalena, en el centro del valle. En esta zona, a pesar del desenfrenado proceso de degradación ambiental moderno, es posible apreciar una elevada diversidad de nichos ecológicos ricos en especies de flora, fauna y tipos de suelos.

El área de estudio en el municipio de Isnos corresponde a una altiplanicie muy disectada formada por colinas de poca altura, con cimas planas extensas, en un gradiente altitudinal que va de 1.650 a $1.900 \mathrm{~m} \mathrm{~s}$. n. m. (figura 4). Al norte, la delimitan los contrafuertes de la cordillera Central, a partir de los $2.000 \mathrm{~m}$ s. n. m.; al oriente, el cauce del río Bordones, que desciende de las cimas de la cordillera Central; al occidente, el profundo cañón del río Mazamorras, que

3 Corresponde a la mayor latitud norte en donde se ha realizado investigación arqueológica de asentamientos (Drennan 2006) que muestran rasgos formales similares a los típicos excavados al sur. 
Figura 1. Área de estudio. Sur del Alto Magdalena

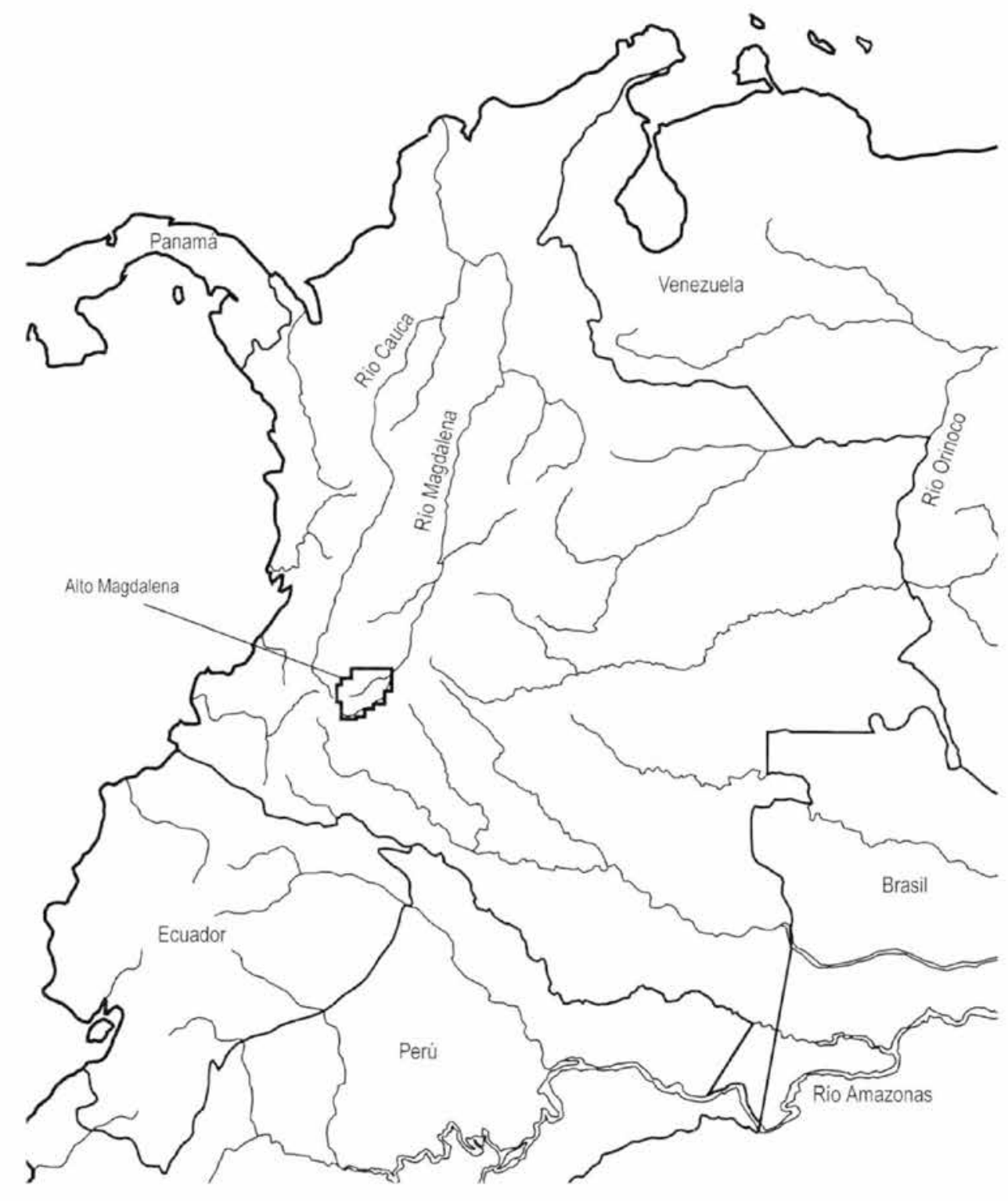

Fuente: Tomado de Drennan $(2000,6)$.

también desciende de esa cordillera, y al sur, el cauce del río Magdalena (figura 2). En este relieve sobresalen varios conos volcánicos inactivos de poca altura, de 1 a 2 kilómetros de diámetro en la base, entre ellos el cerro la Montosa, la Horqueta, Primavera y el Cacique. 
El eje hídrico fundamental, por supuesto, es el río Magdalena; hacia él fluyen numerosas quebradas, que descienden de los contrafuertes de la cordillera Central; entre ellas sobresale la Chorrera, que divide la altiplanicie en dos mitades de similar extensión $\left(50 \mathrm{~km}^{2}\right)$. En el extremo nororiental del área de estudio se encuentra un humedal (Ciénaga Grande) de aproximadamente $3 \mathrm{~km}^{2}$, que seguramente en el pasado proporcionó abundantes recursos ${ }^{4}$. El área corresponde a la provincia de clima medio húmedo, con temperatura media de $19{ }^{\circ} \mathrm{C}$ y precipitaciones pluviales de 1.100 a $1.600 \mathrm{~mm}$ anuales.

Se han identificado dos complejos de suelos que se relacionan por su litología y edad: un relieve volcánico denudativo, seguido por la altiplanicie hidrovolcánica degradada. A la vez, los dos complejos forman dos paisajes básicos: los conos de escoria volcánica y la superficie típica de altiplano de ignimbritas pertenecientes a la formación Guacacallo, compuesta fundamentalmente de tobas y diabasas muy pobres en minerales básicos, necesarios como nutrientes de las plantas, y sobre esta formación, cenizas volcánicas recientes.

\section{Escalas de análisis}

La historia de las condiciones ambientales en la zona estuvo marcada por cambios bruscos prolongados de las temperaturas y precipitaciones que influyeron, por supuesto, en la cobertura vegetal, la fauna y la dinámica poblacional prehispánica. Del 3050 a. C. al 1050 a. C., las condiciones se caracterizaron por temperaturas y precipitación bastante bajas; luego, hasta el 50 a. C., aunque persistieron las temperaturas bajas, se elevó en forma considerable la precipitación. A partir de esta fecha y hasta el $550 \mathrm{~d}$. C., las condiciones mejoraron, pues disminuyó la humedad y aumentó la temperatura; pero de nuevo, y hasta el 1300 d. C., hubo incremento de la precipitación y de la temperatura. Finalmente, a partir de esta época se inició un cambio hacia las condiciones que conocemos en la actualidad (Drennan et al. 1989, 226-232).

El interés por las características de la producción agrícola prehispánica en el sur del Alto Magdalena, particularmente en el territorio del hoy municipio de Isnos, surgió en el ámbito del Programa de Arqueología Regional en el Alto

4 Durante la fase del reconocimiento sistemático se hallaron varias pesas para redes de pesca en los sitios de los alrededores. En este mismo sector, parece, se halló el colgante en forma de pez, actualmente en el Museo del Oro del Banco de la República (MO-N.o 32924) y que aparece en la portada del boletín $n .^{\circ} 22$ del museo. 


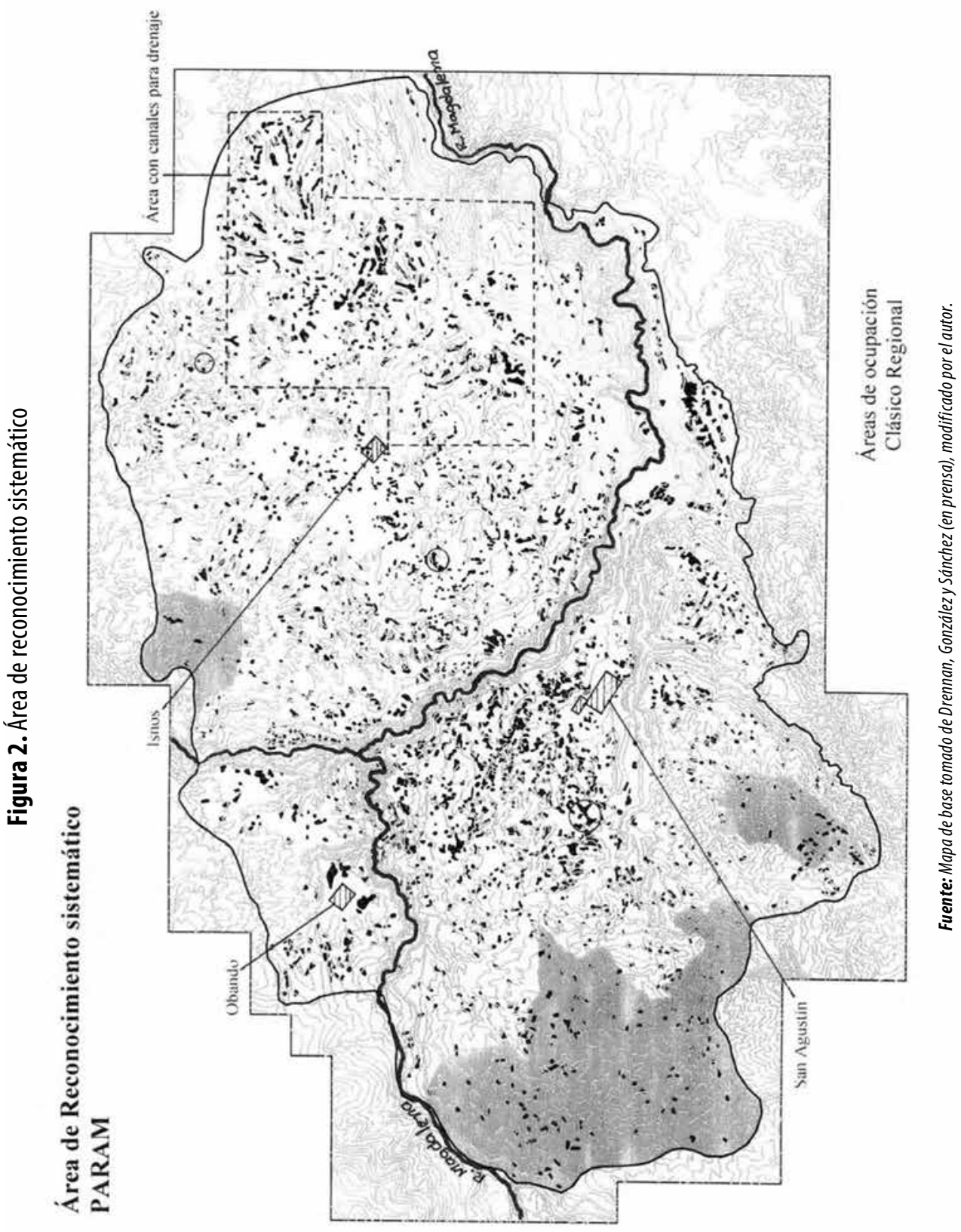


Magdalena (Param); en esta investigación participan el Instituto Colombiano de Antropología e Historia y las universidades de Pittsburgh y Nacional de Colombia, con la dirección general del profesor Robert D. Drennan. El propósito inicial del estudio era indagar sobre los factores que posibilitaron el surgimiento y la consolidación de las sociedades jerarquizadas de tipo cacical; por lo tanto, la técnica básica aplicada para recabar la información indispensable fue el reconocimiento regional sistemático o de cubrimiento total ${ }^{5}$, en una extensión de $350 \mathrm{~km}^{2}$ en los municipios de San Agustín e Isnos (figura 2). Una segunda escala de análisis tenía como objetivo recabar información particular sobre la producción agrícola en una parte del territorio sometida al reconocimiento sistemático; un sector de $50 \mathrm{~km}^{2}$ al oriente de la actual área urbana del municipio de Isnos, que en lo sucesivo llamaré La Marquesa (área delimitada por línea punteada en las figuras 2 y 3). Para obtener la información pertinente, se llevó a cabo un reconocimiento intensivo, con énfasis en el centro-sur de ese sector, que consistió en excavaciones estratigráficas de $1 \mathrm{~m} \times 1 \mathrm{~m}$ de lado por niveles de 10 centímetros de espesor, a intervalos de 40 metros, sobre las cimas de las colinas, que correspondían a las áreas de ocupación mediante viviendas (Sánchez 2005, 25-26). El propósito era obtener macrorrestos botánicos que proporcionaran información cualitativa y cuantitativa de cultígenos a través del tiempo; también se buscaba información sobre contemporaneidad y asociación y diferencias cualitativas entre las plantas de vivienda en esas áreas de ocupación. En total se excavaron 388 cortes en 187 áreas de ocupación, de los cuales se extrajeron 1.502 muestras de suelo (5 litros cada una) para, mediante flotación, extraer macrorrestos botánicos; de ellas, 624 resultaron positivas por la presencia de semillas carbonizadas y mineralizadas, correspondientes a plantas cultivadas y silvestres (Sánchez 2005, 26-32).

Aunque la lista (tabla 1) se refiere a periodos determinados, es bastante probable que algunos cultivos hayan comenzado mucho antes del periodo al que correspondían los depósitos arqueológicos excavados y que la mayoría de ellos hayan continuado hasta épocas tardías. Además de las diversas especies vegetales cultivadas, es obvio que la caza, la pesca y la recolección de recursos silvestres ${ }^{6}$ que se llevaban a cabo en las proximidades de los asentamientos proporcionaron

5 Para una descripción detallada, véase Drennan (1985, 144-180; 2000, 41-53).

6 En el municipio de Isnos, el límite con las áreas boscosas de la cordillera Central, incluyendo el Parque Nacional Natural Puracé, se encuentra a unos $10 \mathrm{~km}$ del casco urbano; se trata de bosques que albergan aún una impresionante variedad de flora y de fauna. También hoy se aprecian amplias áreas cenagosas que en el pasado fueron sistemas lagunares, seguramente ricas en recursos (Ciénaga Grande, Ciénaga Chica, el sector al occidente del pueblo y al suroriente del Alto de Los Ídolos), e igual debió ocurrir con los varios ríos y quebradas que discurren por el territorio del municipio. 
Tabla 1. Cultígenos y periodos

\begin{tabular}{l|c|c|c|c|c}
\hline \multicolumn{1}{|c|}{ Cultígeno } & F. 1 & F. 2 & F. 3 & Clásico & Reciente \\
\hline Achiote (Bixa orellana) & & & & $\mathrm{X}$ & \\
\hline Achira (Canna edulis) & & & & & $\mathrm{X}$ \\
\hline Ají (Capsicum frutescens) & $\mathrm{X}$ & & & & \\
\hline Algodón (Gossipium sp.) & & & $\mathrm{X}$ & & $\mathrm{X}$ \\
\hline Batata (Ipomoea batatas) & & $\mathrm{X}$ & & & \\
\hline Chirimoya (Annona cherimola) & & & & & $\mathrm{X}$ \\
\hline Chontaduro (Gulielma gasipaes) & & & & & $\mathrm{X}$ \\
\hline Coca (Erithroxilum coca) & & & & $\mathrm{X}$ & \\
\hline Frijol (Phaseolus vulgaris) & & & $\mathrm{X}$ & $\mathrm{X}$ & $\mathrm{X}$ \\
\hline Guayaba (Psidium guajava) & & & $\mathrm{X}$ & $\mathrm{X}$ & $\mathrm{X}$ \\
\hline Malanga o bore (Xanthosoma sp.) & & & $\mathrm{X}$ & & \\
\hline Maíz (Zea mays) & & $\mathrm{X}$ & $\mathrm{X}$ & $\mathrm{X}$ & $\mathrm{X}$ \\
\hline Maní (Arachis hipogea)*** & & & & & $\mathrm{X}$ \\
\hline Mora silvestre (Rubus glaucus)* & & & & & $\mathrm{X}$ \\
\hline Nogal (Juglans pyriformis liebm) & & & $\mathrm{X}$ & & \\
\hline Papa (Solanum tuberosum) & & & & $\mathrm{X}$ & \\
\hline Papaya (Carica papaya) & & & $\mathrm{X}$ & $\mathrm{X}$ & $\mathrm{X}$ \\
\hline Platanillo (Heliconia huilensis) ** & & $\mathrm{X}$ & & $\mathrm{X}$ & $\mathrm{X}$ \\
\hline Quinoa (Chenopodium quinoa) & & & & $\mathrm{X}$ & \\
\hline Palma (Prestoea sp) & & $\mathrm{X}$ & $\mathrm{X}$ & $\mathrm{X}$ & $\mathrm{X}$ \\
\hline $\begin{array}{l}\text { Tomate } \\
\text { (Lycopersicum cf. esculentum) }\end{array}$ & & & & $\mathrm{X}$ & $\mathrm{X}$ \\
\hline Uchuva (Physalis (f. peruviana) & & $\mathrm{X}$ & & $\mathrm{X}$ & $\mathrm{X}$ \\
\hline Yuca (Manihot esculenta) & & & $\mathrm{X}$ & & \\
\hline
\end{tabular}

Fuente: Drennan et al. (1989), Duque y Cubillos (1988), Quattrin (2001), Sánchez (2005).

* Frutos silvestres de áreas abiertas.

* Plantas que crecen en zonas húmedas boscosas

***Incluye la variedad guasca que mencionan Duque y Cubillos (1988). 
una elevada cantidad de los alimentos que consumían las comunidades en la zona, con lo que siempre disfrutaron de dietas óptimas o balanceadas.

En el primer semestre de 2014 se llevó a cabo una temporada de campo durante la cual se refinó el reconocimiento intensivo, que se aplicó en tres áreas de ocupación delimitadas en el reconocimiento sistemático. En esta oportunidad se buscó información más detallada sobre la densidad de plantas de vivienda en algunas áreas de ocupación, tanto del sector con canales para drenaje en La Marquesa, sitios SA1442 y SA1712, como en el área aledaña en donde no se realizaron estas adecuaciones de los suelos, sitio SA532 (figura 3). El propósito era comparar las modalidades de los procesos productivos en cuanto a inversión de fuerza de trabajo o magnitud de la participación social en la producción agrícola en extensiones similares de campos de labranza. El reconocimiento se realizó mediante sondeos de $40 \mathrm{~cm} \times 40 \mathrm{~cm}$ de lado (dimensiones solo funcionales), en una grilla de puntos cada 5 metros, tan extensa como la dimensión del área de ocupación.

A pesar de las fuertes y prolongadas variaciones climáticas que en épocas prehispánicas afectaron la zona del sur del Alto Magdalena, no es posible pensar en limitaciones severas para las prácticas agrícolas, al grado de desencadenar conflictos con las comunidades vecinas, tal como ocurre en el modelo de Carneiro (1970, 7-13; 1988, 497-511), salvo las diferencias en cuanto a la fertilidad inherente de los suelos. También se desvirtúa la posibilidad de incremento de las poblaciones hasta el grado de ejercer presión sobre los recursos, pues los estudios arqueológicos realizados por Drennan (2000) y Drennan et al. $(1989,2006)$ señalan crecimiento a tasas constates pero no muy elevadas.

\section{Organización de la producción y estructura política}

Dado que solventar las necesidades conlleva la participación diferencial de los seres humanos en los procesos de trabajo para la producción, toda sociedad requiere y dispone de algún tipo de normatividad, liderazgo y dirección, efímero o estable e institucionalizado. En el Alto Magdalena, es probable que las primeras manifestaciones de liderazgos políticos hayan ocurrido temprano en la historia del desarrollo social, durante el periodo Formativo (1000 a. C.-1 d. C.), pues Duque y Cubillos $(1988,104)$ datan una tumba monumental situada en el Alto de las Piedras (municipio de Isnos) en el 800 a. C. y varias otras durante las dos 


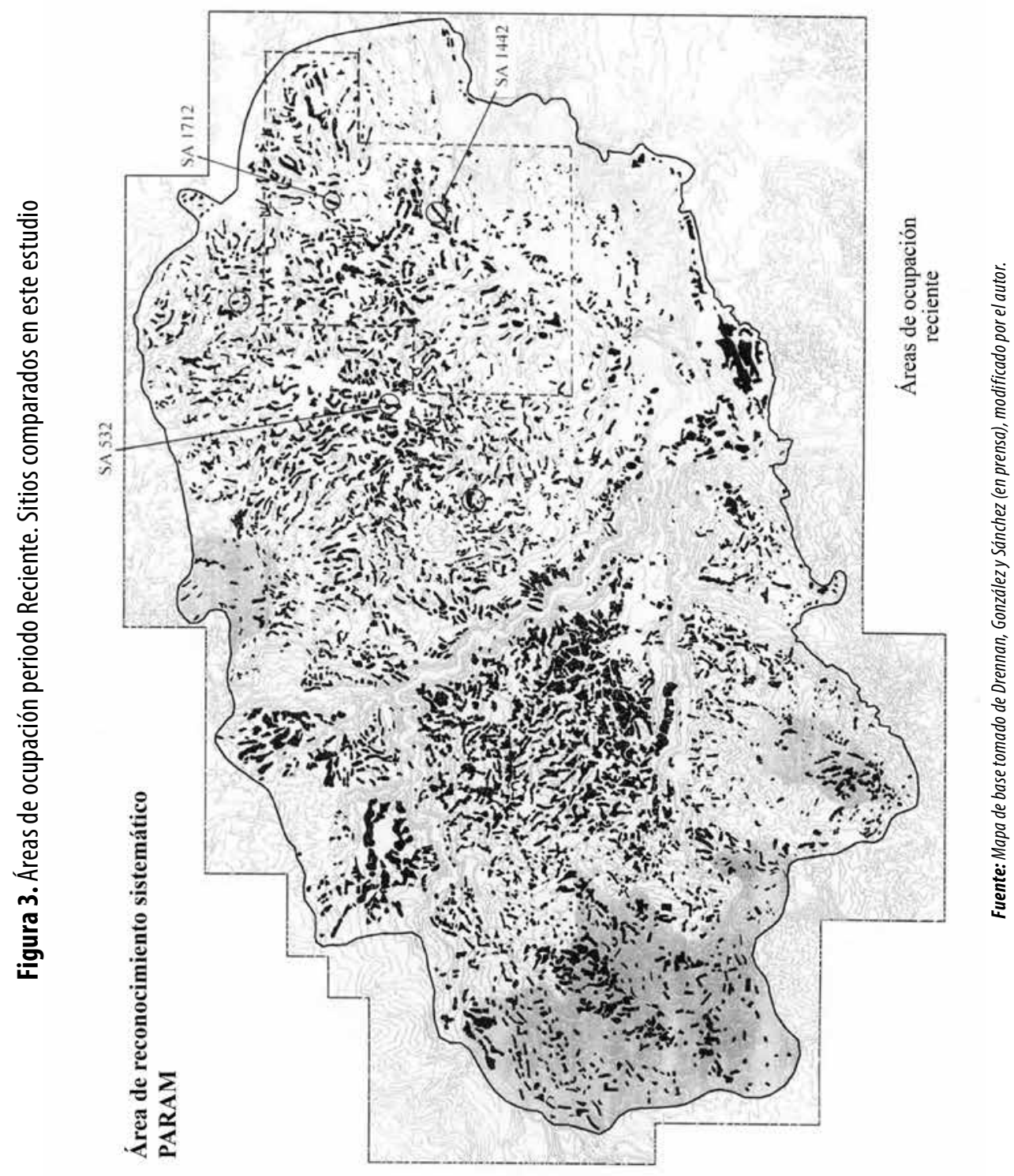


primeras centurias a. C., como el montículo norte de la Mesita B, El Purutal (San Agustín) y el montículo 1 del Alto de los Ídolos (Isnos). Sin embargo, la mayoría de las tumbas monumentales con estatuaria a ellas asociadas corresponden al periodo Clásico Regional (1-900 d. C.). Estas fechas radiocarbónicas y el patrón de asentamiento sugieren que, a finales del Formativo, la población de la zona se encontraba ya segmentada, tal vez en linajes ${ }^{7}$ y sublinajes, seguramente jerarquizados, con acceso desigual, por extensión y calidad, a la tierra de labranza y a los recursos silvestres (Sánchez 2000, 92; 2005, 158-160; 2007a, 27-33; 2007b, 172-174). Se trató, entonces, de un evento de cambio social, porque se definió la sociedad de jefatura; paso cualitativo de suma importancia, pues su estructuración fue la negación de la sociedad comunal (Lee 1990; Saitta 1994; Saitta y Keene 1990) o comunidad doméstica (Meillassoux 1977), cuya reproducción era ya imposible, porque se intervinieron los objetos y medios de producción y surgieron nuevas relaciones sociales.

En esencia, la sociedad de jefatura se fundamenta en el control y apropiación de una parte del trabajo de los comuneros ${ }^{8}$ en beneficio de un reducido grupo de individuos a cuya cabeza se halla quien funge como líder de la comunidad. La apropiación de esa parte del trabajo tiene como fin auspiciar las instituciones e iniciativas impulsadas por el líder y su séquito; consiste en la transferencia de recursos y servicios, ya sea en forma obligatoria, enmascarada como regalo o, con frecuencia, a través de normas que sacralizan algunas instituciones, como la consagración de fiestas y rituales a las deidades de la comunidad. En otras palabras, la cesión de bienes y servicios, denominada tributación, es la condición indispensable para la reproducción de la estructura social cacical.

La segmentación jerárquica, con su inherente desigualdad económica y política, se puede deducir de la magnitud monumental de los centros funerarios, su distribución en el paisaje y su ubicación en relación con la calidad agrícola de los suelos. En Isnos se encuentran dos centros funerarios de magnitud sobresaliente, distanciados $14 \mathrm{~km}$ uno de otro, separados por la quebrada La Chorrera, que divide el territorio en dos mitades de más o menos 50 km² de extensión cada una (figura 4).

7 La segmentación de las comunidades del sur del Alto Magdalena fue planteada por Duque (1964, 377-381), pero él no la asoció con la división territorial y la desigualdad en el acceso a la tierra por parte de los segmentos.

8 Se trata de lo que el marxismo denomina trabajo excedente (Marx [1875] 1971), cuya importancia radica en las condiciones sociales de su apropiación. Excedente no se refiere a la producción que excede la solución de las necesidades básicas, sino a una cantidad de productos y servicios a disposición de la sociedad para propósitos específicos. 
Figura 4. Jerarquía de los centros funerarios

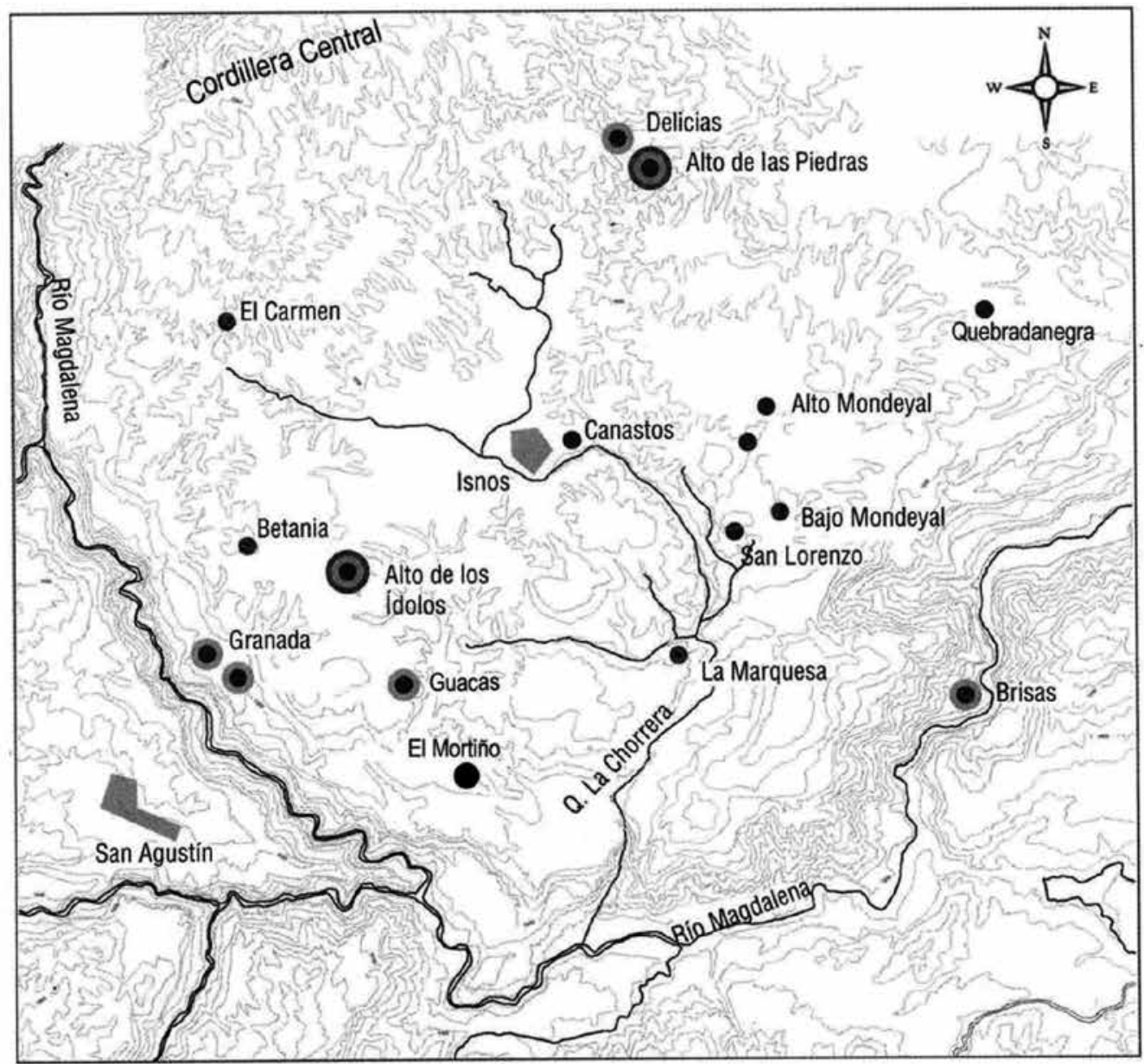

Municipio de Isnos - Jerarquía de los centros funerarios

(9) Centro funerario de primer nivel

- Centro funerario de segundo nivel

- Centro funerario de tercer nivel

Cabecera municipal

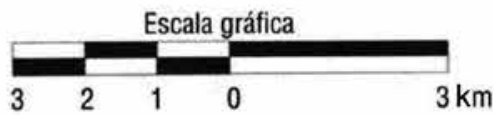

Ríos y quebradas

Cota de nivel

Fuente: Tomado de Sánchez (2007a, 28). 
En la mitad oriental del territorio sobresale el Alto de las Piedras como centro funerario de primer orden. Está ubicado en una unidad agrológica, hoy de buen potencial para la producción agrícola (Sánchez 2007a, 35-36). Se trata de un centro conformado por cuatro montículos funerarios, con tumbas profundas en forma de cancel o una estructura de semicancel que contienen un sarcófago monolítico, un templete y esculturas asociadas cubiertas por túmulos artificiales de tierra. Aunque no se dispone de información cronológica precisa sobre la época de construcción, diseminados en forma amplia en otras unidades agrológicas próximas se encuentran sitios funerarios más discretos, constituidos por uno o dos montículos funerarios de dimensiones reducidas que cubren sarcófagos monolíticos dentro de semicanceles, con un pequeño templete: Bajo Brisas, un montículo; Quebradanegra, un montículo con sarcófago monolítico; Mondeyal, tres montículos, uno de los cuales cubría un sarcófago monolítico; Bajo Mondeyal, un montículo; Canastos, dos montículos, que no han sido excavados ni alterados; San Lorenzo, un montículo, y La Marquesa, un montículo con sarcófago monolítico.

Aunque el potencial productivo de los suelos varía en forma permanente, es bastante probable que las condiciones adversas en el sector de La Marquesa, ocupado esencialmente a partir del Formativo 2 (Sánchez 2007a, 47), hayan sido la razón por la que se evitó su ocupación temprana. Esto ocurrió cuando los últimos segmentos sociales que se conformaron no tenían opción de acceder a otras tierras de mejor calidad para la producción. Los suelos en este sector se desarrollaron en laderas de dos conos volcánicos; son profundos, aunque a 40 centímetros en promedio presentan un horizonte argílico endurecido, con preponderancia de agregados orgánico-arcillosos. Estos factores generan drenajes superficiales y subsuperficiales deficientes, razón por la cual, al permanecer anegados, mantienen temperaturas bajas que impiden la actividad microbiana y el desarrollo radicular (Sánchez 2007a, 34-38).

Esta situación, que ocurre en un área relativamente reducida, nos lleva a considerar otro aspecto de suma importancia en relación con la producción y la política en las sociedades de la historia antigua: la participación social en los procesos de trabajo es, en buena medida, determinada por la modalidad del parentesco y por las condiciones ambientales naturales. En consecuencia, es evidente que en la economía se conjugan dos aspectos interdependientes que deben ser identificados a cabalidad: el proceso productivo físico o proceso de trabajo y la organización social del proceso. En otras palabras, la organización social de la producción implica diversos arreglos y participación variable de los individuos, de las unidades domésticas y del segmento de adscripción inmediata.

Sin duda, la segmentación social y la adscripción a determinados territorios en forma desigual constituyen, en estricto, un hecho económico definido por 
el sistema de parentesco. Este precisa, para los segmentos, el derecho y usufructo del objeto fundamental de la producción: la tierra agrícola, y si ello fue así, se trató del control posibilitado por el ámbito político. Ahora bien, puesto que todo conjunto de relaciones sociales debe legitimarse para lograr su reproducción, la segmentación jerárquica y la estratificación de las comunidades del Alto Magdalena se dieron mediante parafernalias y actos de tipo religioso; en este caso, el parentesco se valió de la religión para reproducir la estructura jerárquica, estratificada y tributaria. A ello obedece la monumentalidad funeraria que, aunque tipificada en el ámbito regional, muestra en forma inequívoca drásticas diferencias de prestigio social y jerarquía política de los personajes inhumados en los centros funerarios y de los segmentos sociales a los que pertenecían, fundamentalmente durante el periodo Clásico Regional (1-900 d. C.). Durante ese lapso, precisamente, se erigieron los pequeños montículos funerarios en los asentamientos del sector de La Marquesa.

A pesar de la importancia de las relaciones sociales de producción, en este caso establecida por el parentesco que gobernaba la vida económica, sorprende que algunos investigadores, basados en las variadas dramatizaciones del ámbito funerario monumental, persistan en afirmar que el sistema político imperante en el Alto Magdalena durante el periodo Clásico Regional tuvo exclusivamente un sustrato ideológico de tipo religioso. Una cualidad enunciada hace mucho tiempo por la economía política y la antropología es que en esas formaciones sociales la función de la religión, e incluso del parentesco, era maquillar, esconder relaciones sociales de producción reales. En esas sociedades, las relaciones sociales de producción se manifestaban en forma de relaciones no económicas, como las prescritas por el parentesco o la religión, aunque en un nivel avanzado de desarrollo lo hacían mediante lo político. A través de dichas relaciones se accedía a los medios de producción, se organizaba el trabajo y se movilizaba el producto logrado. Esto implica que también los ámbitos no enteramente económicos debían ser reproducidos en forma permanente.

En casos como el del Alto Magdalena, independientemente de la carga ideológica de carácter religioso de la inhumación y del simbolismo implícito en la parafernalia de la práctica funeraria, la materialización de la jerarquía política y de la estratificación económica manifiestas en la elaboración del complejo funerario (que incluía la excavación de la tumba, el acarreo de las lajas para la construcción del cancel, el tallado del sarcófago monolítico, el transporte de las lajas para la construcción del templete, el tallado de las esculturas, el acarreo de la tierra y su amontonamiento para formar un montículo) demandaba inversión de energía humana, de trabajo excedente que privilegiaba a unos pocos 
individuos en el seno de la comunidad. En este caso, la apropiación de la fuerza de trabajo excedente apuntalaba el prestigio y liderazgo de un pequeño grupo familiar mediante la magnificación de los ascendientes o ancestros. Por lo tanto, es erróneo el razonamiento formal emanado de la economía de mercado que hace énfasis en calcular costos y beneficios en la producción, porque supuestamente en el pasado lejano, igual que hoy, debió primar el menor esfuerzo para acceder a la tierra de labranza y a los recursos deseados.

No importa cuánto tiempo ni cuántos individuos fueron necesarios para la construcción de las estructuras funerarias. Lo verdaderamente determinante es que las cabezas de unos segmentos sociales se apropiaban del trabajo excedente de los comuneros; inicialmente, tal vez, del producido por los parientes miembros de la unidad doméstica y del segmento de adscripción inmediata, un acto que, llanamente, era de control económico. Así que no es procedente plantear que la evidencia fundamental del control de la economía por parte de los líderes sea la acumulación de bienes de riqueza llevada a cabo por ellos o la presencia de artículos suntuarios depositados como ofrenda funeraria en sus tumbas, pues el estatus, el prestigio, la riqueza pueden haber sido el resultado del control de la fuerza de trabajo invertida en la producción de recursos críticos o haber estado representados en objetos con alta carga simbólica; en el caso del Alto Magdalena, por la parafernalia y arquitectura funeraria monumental. El control de la vida económica en las sociedades del pasado no necesariamente se traducía en la acumulación de bienes de prestigio, sino en la posesión de un estatus sobresaliente, la disposición de prestigio, el control de la distribución de los resultados del trabajo excedente, todo con el propósito de actuar en pos del liderazgo para beneficiar al segmento social al que se pertenecía y así lograr su perpetuación.

Por otra parte, además de la materialización de la segmentación jerárquica que se plasma en el paisaje con la monumentalidad funeraria erigida, es necesario pensar que los actos fúnebres usualmente incluían diversos rituales y ceremonias y que ellos, para mayor efectividad social, comprendían la participación activa, en primera instancia, del grupo familiar inmediato del individuo por inhumar, pues era el grupo que, a la postre, obtendría los mayores beneficios del engrandecimiento del difunto; en segundo lugar, se precisaba de la participación de los parientes miembros del segmento o linaje del personaje para mantener la sujeción y consolidar la primacía de ese conglomerado sobre el resto de la comunidad. Estos ceremoniales generalmente acarreaban erogaciones: era necesario asegurar los insumos materiales indispensables para llevar a cabo las ceremonias, subvencionar al oficiante de los ritos y proporcionar alimentos y bebidas a los asistentes pertenecientes a los otros segmentos de la comunidad, 
de otras unidades políticas y a los comuneros del segmento del difunto. ¿Quién subvencionaba esos gastos? Y ¿cómo se obtenían los recursos indispensables? Seguramente, las erogaciones corrían por cuenta de los miembros del segmento al que pertenecía el difunto.

A partir del 900 d. C. (periodo Reciente, 900-1530 d. C.) ocurrieron profundos cambios culturales al unísono con el fortalecimiento de la estructura cacical. Se abandonó el arte funerario monumental en la región. Durante este tiempo, se enterró tanto a los miembros de las élites como a los comuneros en tumbas de pozo con cámara lateral, estructuras cuya elaboración demandaba menos dedicación y en las que se depositaban ofrendas funerarias discretas, usualmente unos pocos recipientes de uso cotidiano. La cerámica perdió la calidad y la profusa variedad decorativa. Los datos sobre el poblamiento logrados por el reconocimiento sistemático indican que, durante este periodo, las áreas de ocupación en el sector de La Marquesa aumentaron un 22 \% con respecto al periodo anterior (Clásico Regional), pero la población se incrementó un 62 \% (Sánchez 2005, 93, 2007a, 49-50), aumentos que son similares a los del valle de La Plata en su parte occidental, durante el mismo lapso (Drennan 2000, 55-58).

Avanzado el periodo Reciente, probablemente después del año 1000 d. C., en unas condiciones de alta precipitación pluvial (Drennan et al. 1989, 226-232) y de incremento de la población en el sector, los suelos, con sus severas limitaciones para los cultivos, fueron trasformados mediante obras de ingeniería que elevaban el potencial productivo y permitían el laboreo más frecuente y prolongado de las mismas unidades de tierra. Se incrementó la construcción de sistemas de canales para drenaje de los campos agrícolas en el sector La Marquesa, al oriente del actual municipio de Isnos (figuras 5 y 6), con lo que se logró producir los alimentos indispensables para las unidades domésticas y para los pequeños conjuntos conformados por esas unidades, tal vez sublinajes que cooperaban en algunas fases del proceso productivo, y un aumento considerable del trabajo excedente que era apropiado por la comunidad y por la dirección de la unidad política.

La información lograda mediante el reconocimiento sistemático, con muestreo efectuado a intervalos de 50 metros a 80 metros (sondeos y recolecciones superficiales), en términos generales, sugiere que hubo crecimiento de la población a tasas constantes, aunque un poco elevadas durante el periodo Reciente de la cronología regional, es decir, del 900 al 1550 d. C. (Drennan, González y Sánchez en prensa). Sin embargo, los datos que proporcionó el reconocimiento intensivo efectuado en el sector de La Marquesa, con cortes de $1 \mathrm{~m} \times 1 \mathrm{~m}$ de lado, excavados a intervalos de $40 \mathrm{~m}$, muestran un comportamiento del uso del 
Figura 5. Área con sistemas de canales para drenaje al oriente de Isnos

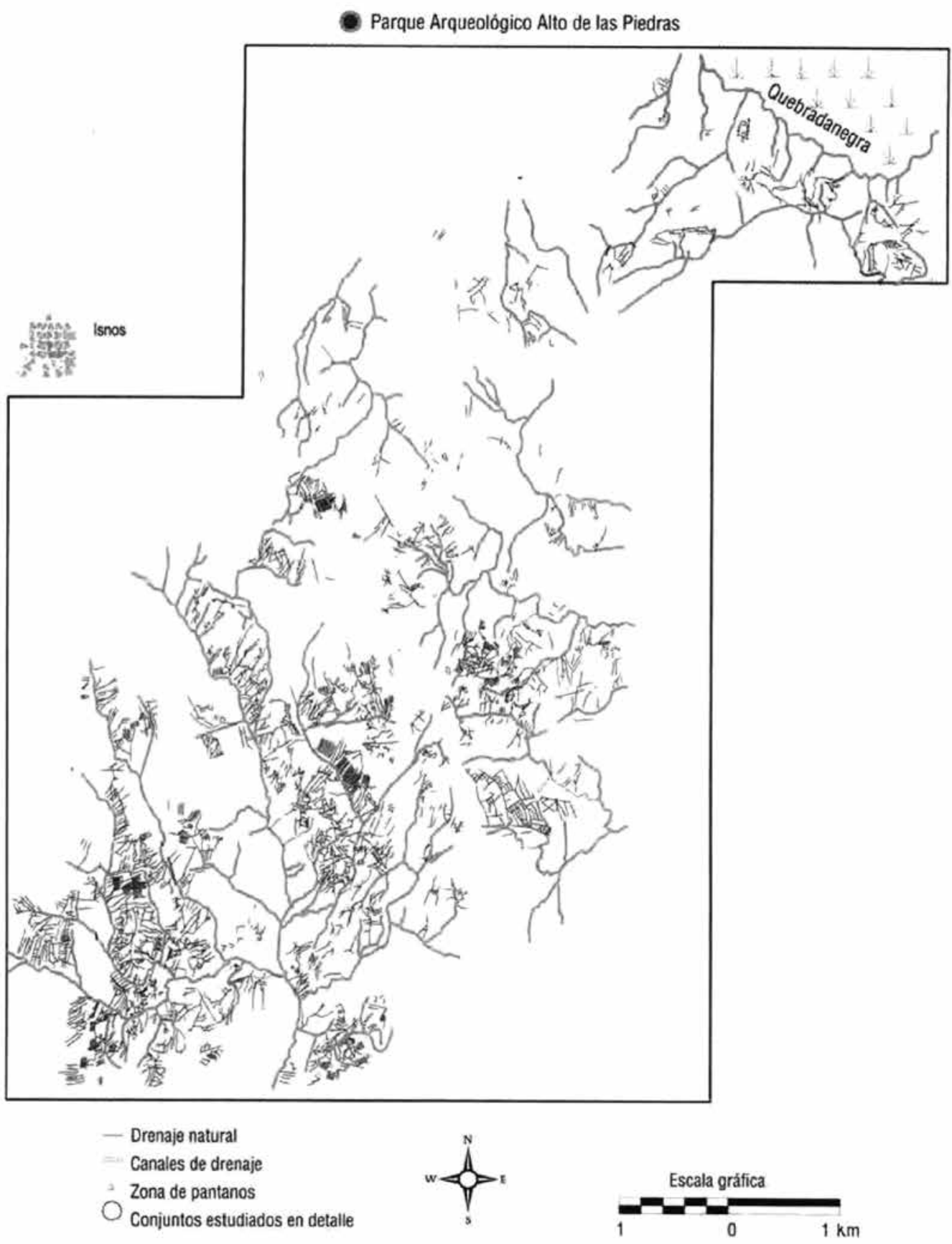

Fuente: Tomado de Drennan, González y Sánchez (2015). 
Figura 6a. Canales para drenaje. Vereda Bajo Mondeyal

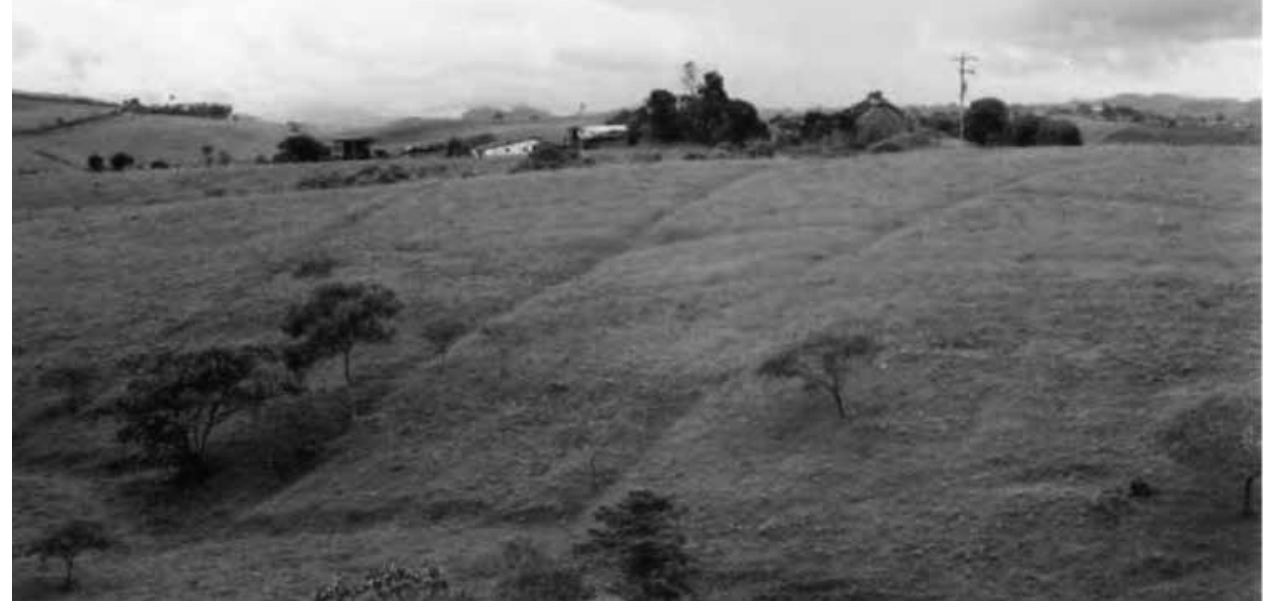

Fuente: Sánchez $(2007,74)$.

Figura 6b. Canales para drenaje y eras para cultivo. Vereda San Lorenzo

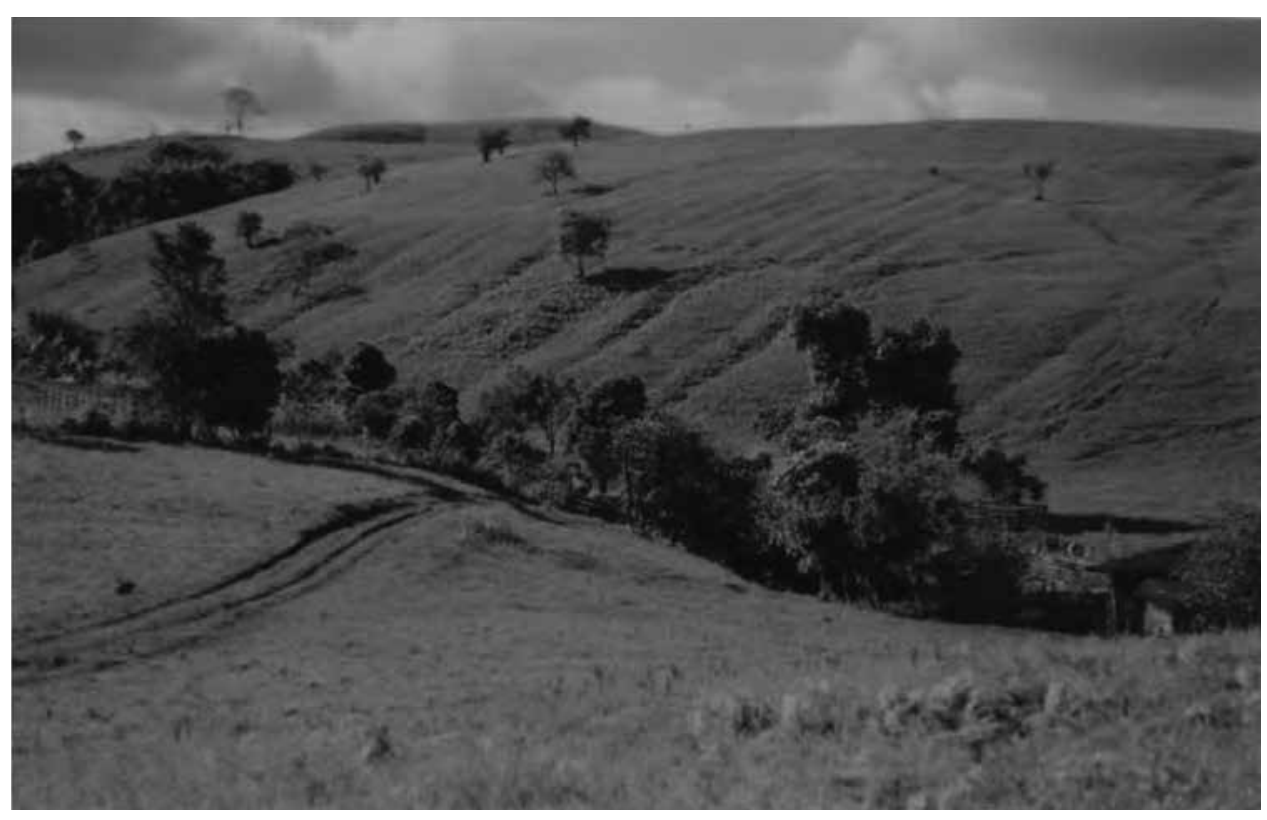

Fuente: Sánchez $(2005,17)$. 
espacio bastante diferente al que se aprecia en los mapas del reconocimiento sistemático que aparecen en las figuras 2 y $3{ }^{9}$. Aunque, efectivamente, hubo aumento de la cantidad de desechos domésticos, especialmente de fragmentos de cerámica, indicio de mayor población (Sánchez 2005, 23-24), disminuyó la cantidad de áreas de ocupación, y sobre todo se redujeron las extensiones de las que continuaron ocupadas (Sánchez 2005, 23-54; 2007a, 40-51) ${ }^{10}$. ¿Qué propició este fenómeno? Tal como señalé en las publicaciones recién citadas, y como lo ratificaron las prospecciones intensivas realizadas en el año 2014 en tres áreas de ocupación, las viviendas fueron reubicadas y, en algunos casos, posiblemente, se construyeron estructuras que albergaban familias extensas; ello explica la concentración y alta densidad de material cerámico hallado en algunos sectores de las áreas de ocupación.

La dinámica observada de los patrones de asentamiento, en la que contrastan el área con sistemas de canales para drenaje y las áreas aledañas en las que no fue preciso efectuar estas obras de adecuación de los suelos, sugiere diferencias en la magnitud de la participación social en los procesos de trabajo, fundamentalmente de las unidades domésticas. En consecuencia, nos dimos a la tarea de cotejar esa diferencia mediante la prospección intensiva de campos agrícolas de extensiones similares, pero con las disímiles características de los suelos para su laboreo. En la zona con sistemas de canales para drenaje de los suelos se realizaron prospecciones en los sitios o áreas de ocupación SA1442 (figura 6a) y en SA1712, campos de aproximadamente 3 hectáreas cada uno. En la zona aledaña al occidente, en donde no se construyeron drenajes, se efectuó la prospección en el sitio SA532, y se obtuvo evidencia fehaciente de ocupación como asentamiento, con similar extensión de terreno agrícola.

La prospección intensiva se efectuó sobre los terrenos óptimos para la construcción de viviendas; se trata siempre de las cimas planas de las colinas, en donde se inician los sistemas de canales para drenaje de los campos agrícolas que corresponden a las laderas (véase Sánchez 2007a, 59-90). En el sitio SA1442, se marcó una grilla con 216 sondeos de $40 \mathrm{~cm} \times 40 \mathrm{~cm}$ de lado ${ }^{11}$ y 50 centímetros

9 Para mayor certeza, compárense los cálculos y figuras de Sánchez (2007a, 40-51) con los mapas generados en el Param.

10 Por sitio o área de ocupación en el Param se entiende el espacio sobre el que se hallan evidencias de actividad antrópica, especialmente desechos de actividad doméstica; por lo tanto, las áreas en donde estuvieron emplazadas las viviendas. Esta, por supuesto, es una consideración reduccionista, aunque con justificación funcional, que deja de lado las áreas aledañas a las viviendas, dedicadas a las actividades agrícolas. 
de profundidad ${ }^{12}$, distanciados 5 metros uno de otro; igual procedimiento se siguió para la grilla de 159 sondeos que se excavaron en el sitio SA1712, y para la excavación de los 286 sondeos en el sitio SA532.

Para las evaluaciones sobre distribución y densidades de fragmentos de cerámica por periodos en las áreas de ocupación se utilizó el programa Surfer 11, que requiere como variables la localización de los sondeos (coordenadas x-y) y la cantidad de fragmentos de cerámica por periodo, a partir de lo cual genera mapas que señalan la distribución diferencial del material en el terreno prospectado; por lo tanto, también de los espacios libres de desechos, en donde probablemente estuvieron ubicadas las viviendas de quienes produjeron dichos desechos. Las evaluaciones realizadas son elocuentes en relación con las variaciones demográficas. Aunque en algunos sondeos hechos en el sitio SA1442 se halló material cerámico correspondiente al periodo Formativo, solamente se consideran aquí el concerniente a los periodos Clásico Regional y Reciente, porque está vinculado con la implementación de los sistemas de drenaje. En SA1442, la media de fragmentos relativa al periodo Clásico Regional fue de 3,7 y, en SA1712, de 4,2, mientras que durante el periodo Reciente se elevó a 4,5 y 6,3 respectivamente.

Así mismo, las densidades de cerámica en esas áreas en los dos periodos (figuras 7 y 8) difieren en forma notable: en SA1442 se detectaron cinco concentraciones del periodo Clásico Regional, correspondientes a igual cantidad de viviendas, aunque posiblemente no todas contemporáneas, y avanzado el periodo Reciente, cuando se construyeron los sistemas de canales, la cantidad de viviendas se redujo a cuatro. Una de ellas, la del extremo izquierdo en la figura 7, se halla sobre el trazado de un canal y, según sugiere la disposición de los desechos, está ubicada en sentido contrario al resto del asentamiento; por lo tanto, aunque debió corresponder a la ubicación de una estructura habitacional de ese periodo, fue anterior a la construcción del sistema de canales. Algo igual sucedió en el área SA1712 (figura 8), que muestra cinco concentraciones durante el periodo Clásico Regional, no necesariamente contemporáneas, mientras que solo tres durante el Reciente. Sin embargo, la de la derecha debió ser resultado de una vivienda habitada por poco tiempo (baja densidad de desechos) a comienzos del periodo, pues se encuentra sobre uno de los canales que se inicia en el sitio. 
Figura 7a. Mapa de cota de densidades de cerámica, SA1442. Periodo Clásico Regional

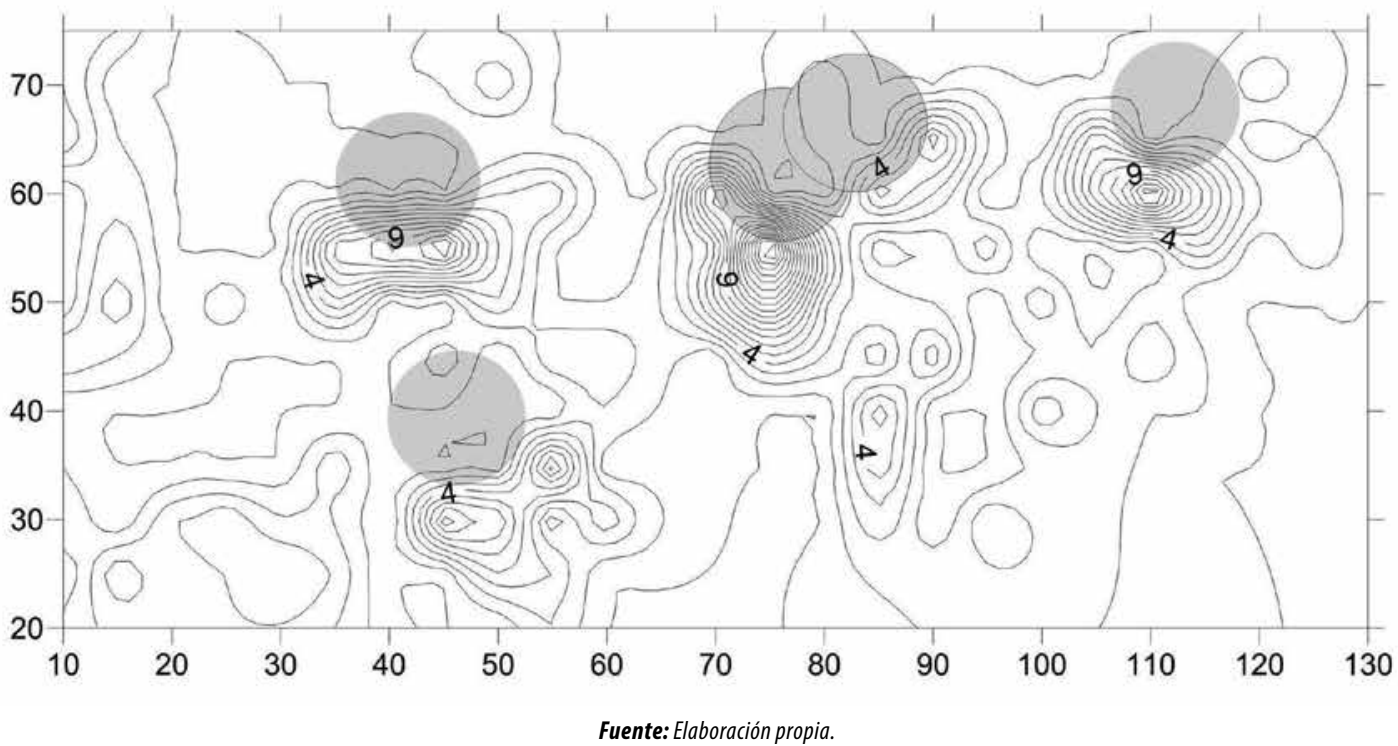

Figura 7b. Mapa de cota de densidades de cerámica, SA1442. Periodo Reciente

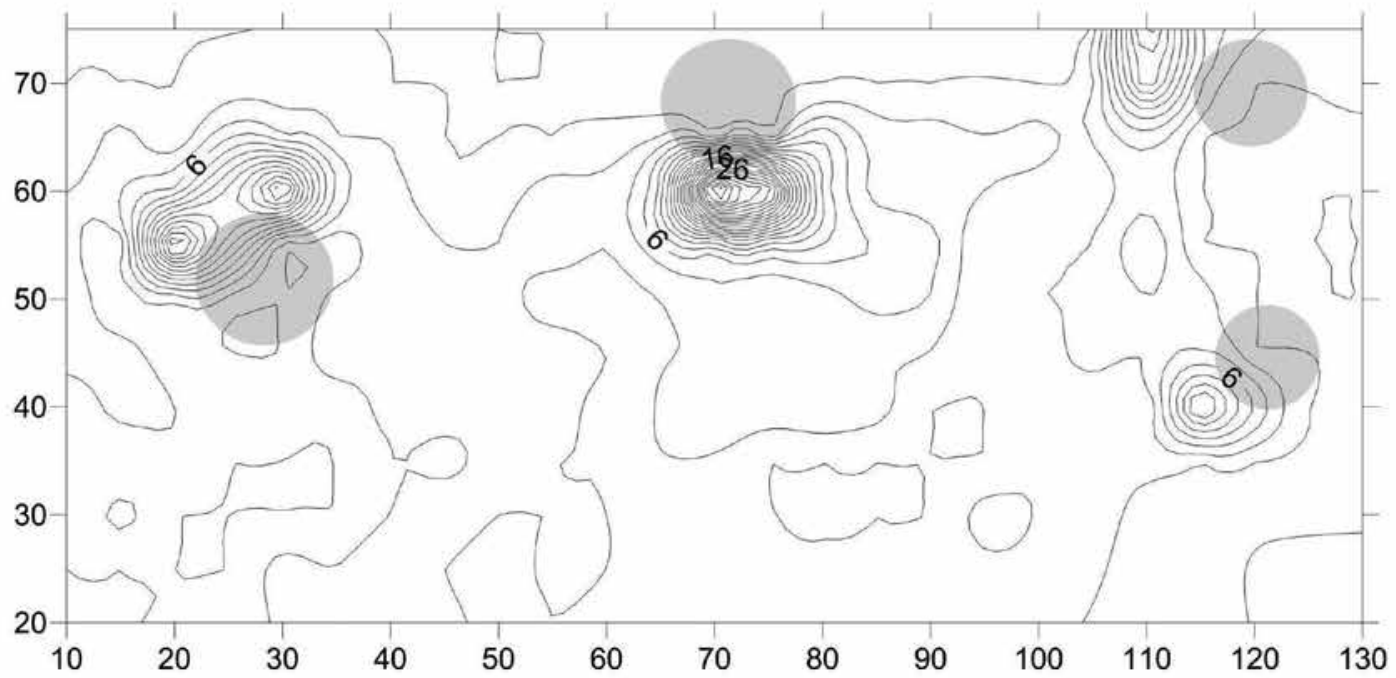

Fuente: Elaboración propia. 
Figura 8a. Mapa de cota de densidades de cerámica, SA1712. Periodo Clásico Regional

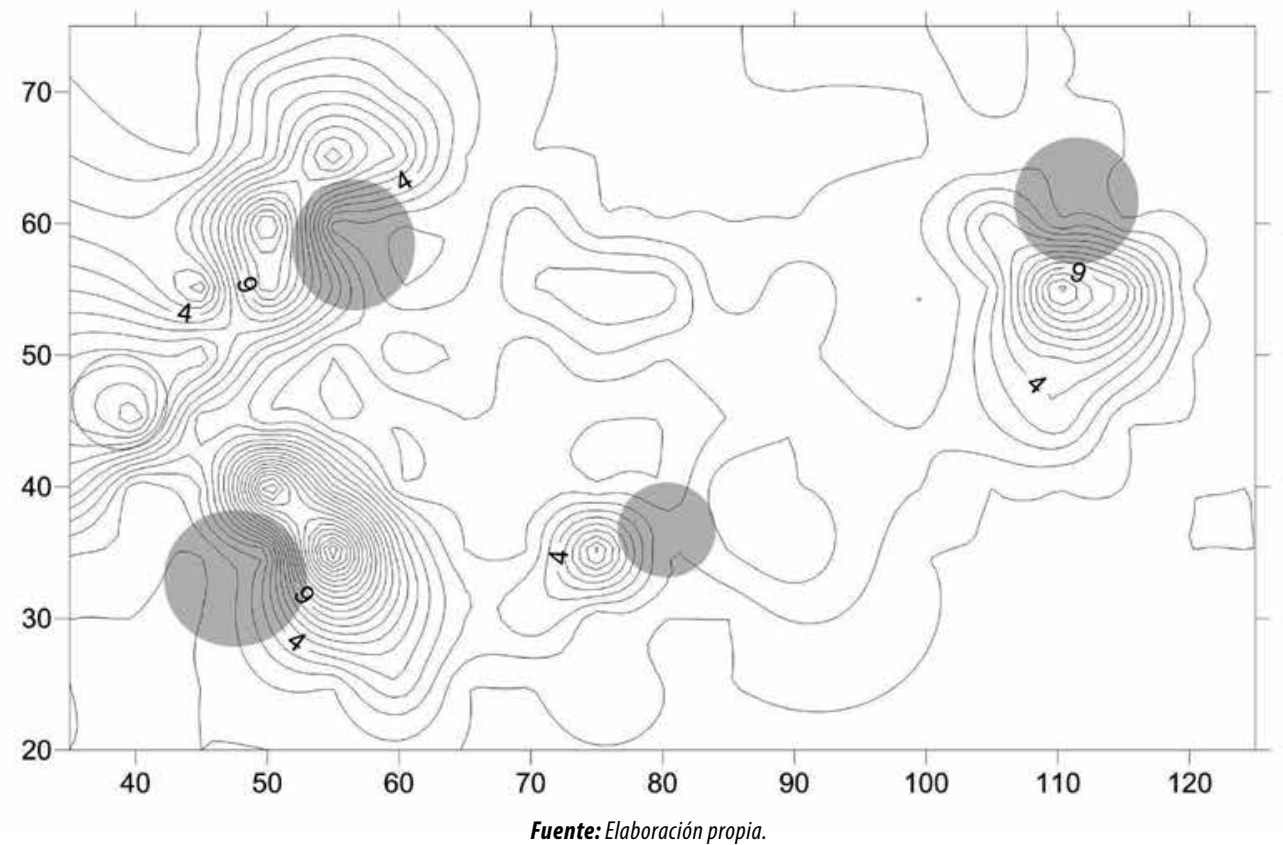

Figura 8b. Mapa de cota de densidades de cerámica, SA1712. Periodo Reciente

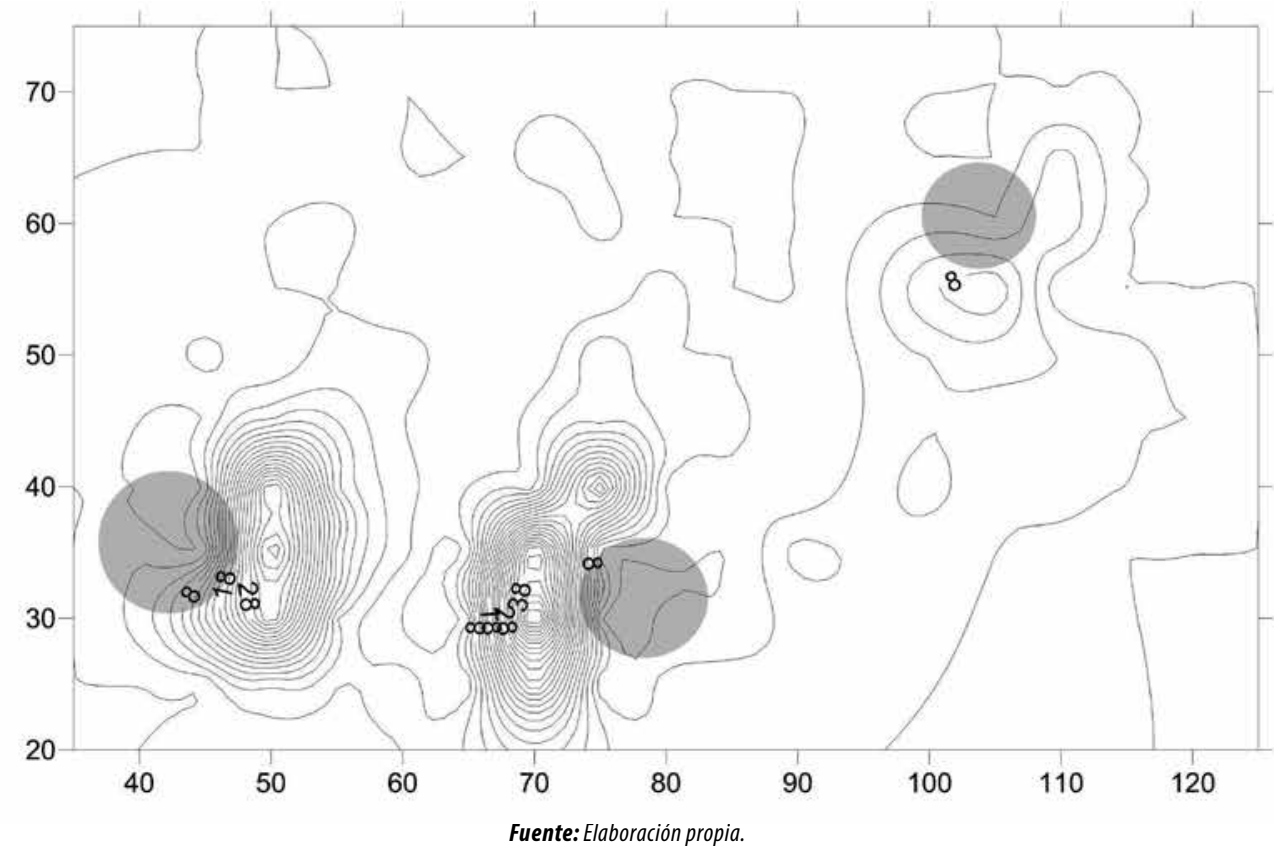


Al tiempo, en los terrenos de áreas vecinas, especialmente hacia el occidente, con condiciones más benignas para la producción agrícola, no fue necesario construir los sistemas de drenaje, y podría pensarse que cada unidad doméstica disponía y trabajaba su parcela sin recurrir necesariamente a la fuerza de trabajo de otras unidades. Sin embargo, la densidad y distribución espacial de la cerámica por periodo difiere de lo que se observa en la zona con sistemas de canales; aquí disminuyó la cantidad de desechos domésticos, entre ellos la media de fragmentos de cerámica, que pasó de 8,9 durante el Clásico Regional a 5,1 durante el Reciente. No sucedió lo mismo con las concentraciones de desechos domésticos (figura 9), pues de 2 en el Clásico aumentaron a 4 en el periodo Reciente. ¿Qué pudo pasar? Posiblemente, las condiciones de mayor potencial agrícola permitieron la ocupación de la colina por unidades familiares mucho más pequeñas que se sucedieron por un lapso más prolongado. Esto significa que las viviendas de donde procedieron los desechos no fueron contemporáneas, que el sitio fue ocupado en forma simultánea solamente por unas dos unidades domésticas que habitaban casas separadas.

Parece claro que el periodo Reciente se caracterizó por el dominio de la economía tributaria, en la que el trabajo excedente, representado fundamentalmente por productos críticos y de alta demanda, ocurría en procesos productivos con ambientes tecnológicos disímiles: agricultura intensiva, definida por los campos de labranza con sistemas de canales para drenaje, de uso frecuente y prolongado, y agricultura en tierras de labranza con suelos óptimos para la producción, en donde no eran necesarias las obras de adecuación. Estos ambientes, por supuesto, demandaban diferentes formas de organización del trabajo. En consecuencia, por lo menos en el territorio del actual municipio de Isnos en épocas prehispánicas, los procesos productivos en la economía tributaria cacical comprendían inversiones de energía (trabajo) diferenciales. Eran bastante mayores en el caso de la agricultura intensiva ya que, además de la tributación o la entrega del resultado del trabajo excedente, era necesario construir y mantener los sistemas de canales.

La evidencia histórica indica que la tributación de los comuneros a los caciques ocurría todavía a comienzos del siglo XVI, cuando arribaron los conquistadores españoles. En esa época tardía, y aun tratándose de cacicazgos más complejos que los imperantes durante el periodo Clásico Regional, el parentesco continuaba gobernando la estructura de las relaciones sociales, pero las comunidades se habían extendido de tal forma que comenzaban a primar relaciones de tipo político. Es posible que se tratara de un sistema de filiación matrilineal, en el que Pigoanza era el cacique regional principal en el sur del Alto Magdalena, su 
Figura 9a. Mapa de cota de densidades de cerámica, SA532. Periodo Clásico Regional

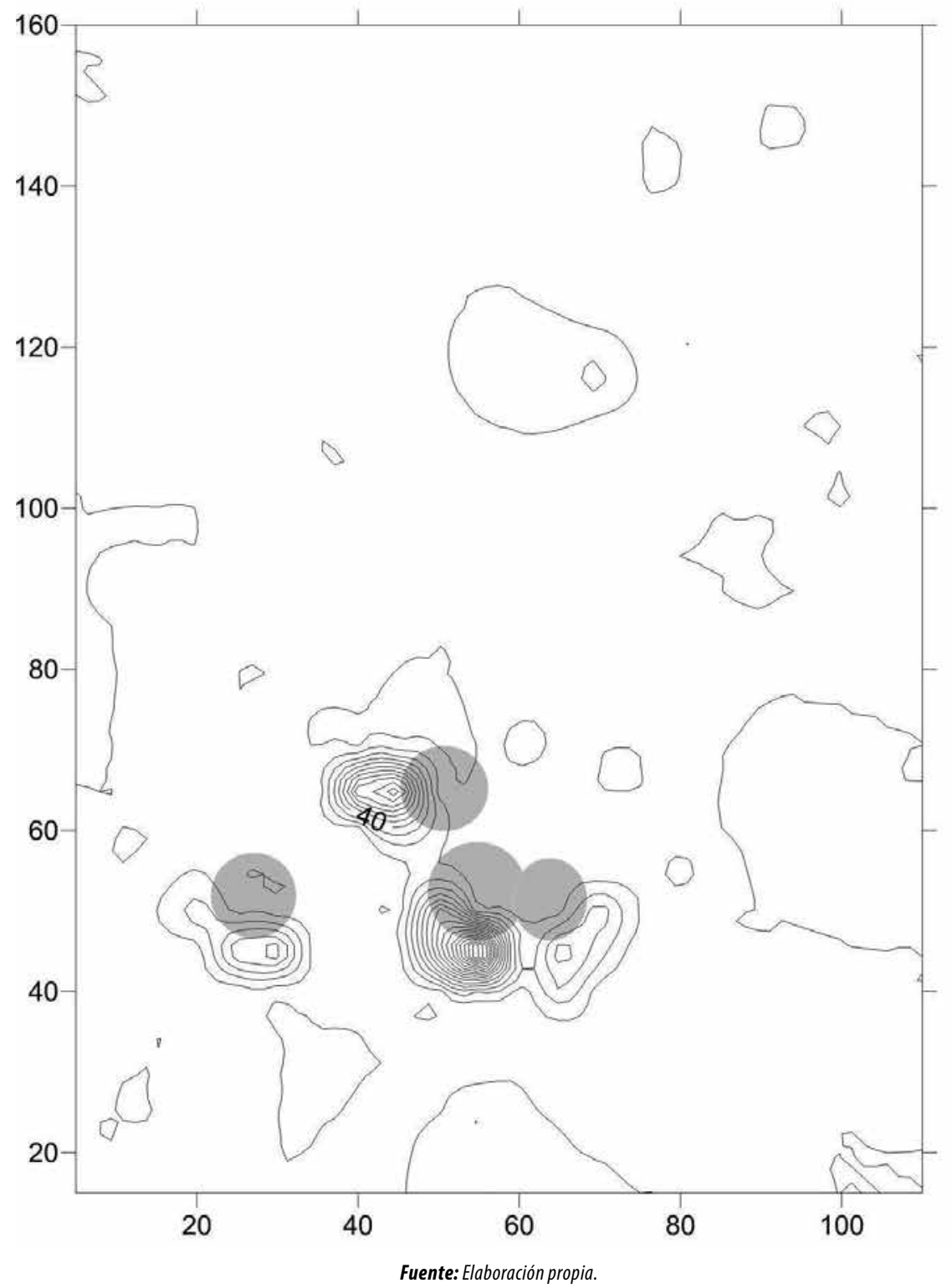

hermano Pirama y su tío Meco se desempeñaban como caciques secundarios bajo su liderazgo y, probablemente, Timanco, su sobrino, hijo de La Gaitana, hermana de Pigoanza, lo sucedería en el cargo de cacique regional (Sánchez 2007a, 32-33).

A propósito de la tributación, Juan Friede transcribe algunas declaraciones recogidas por el oidor Tomás López casi una centuria después de la conquista 
Figura 9b. Mapa de cota de densidades de cerámica, SA532. Periodo Reciente

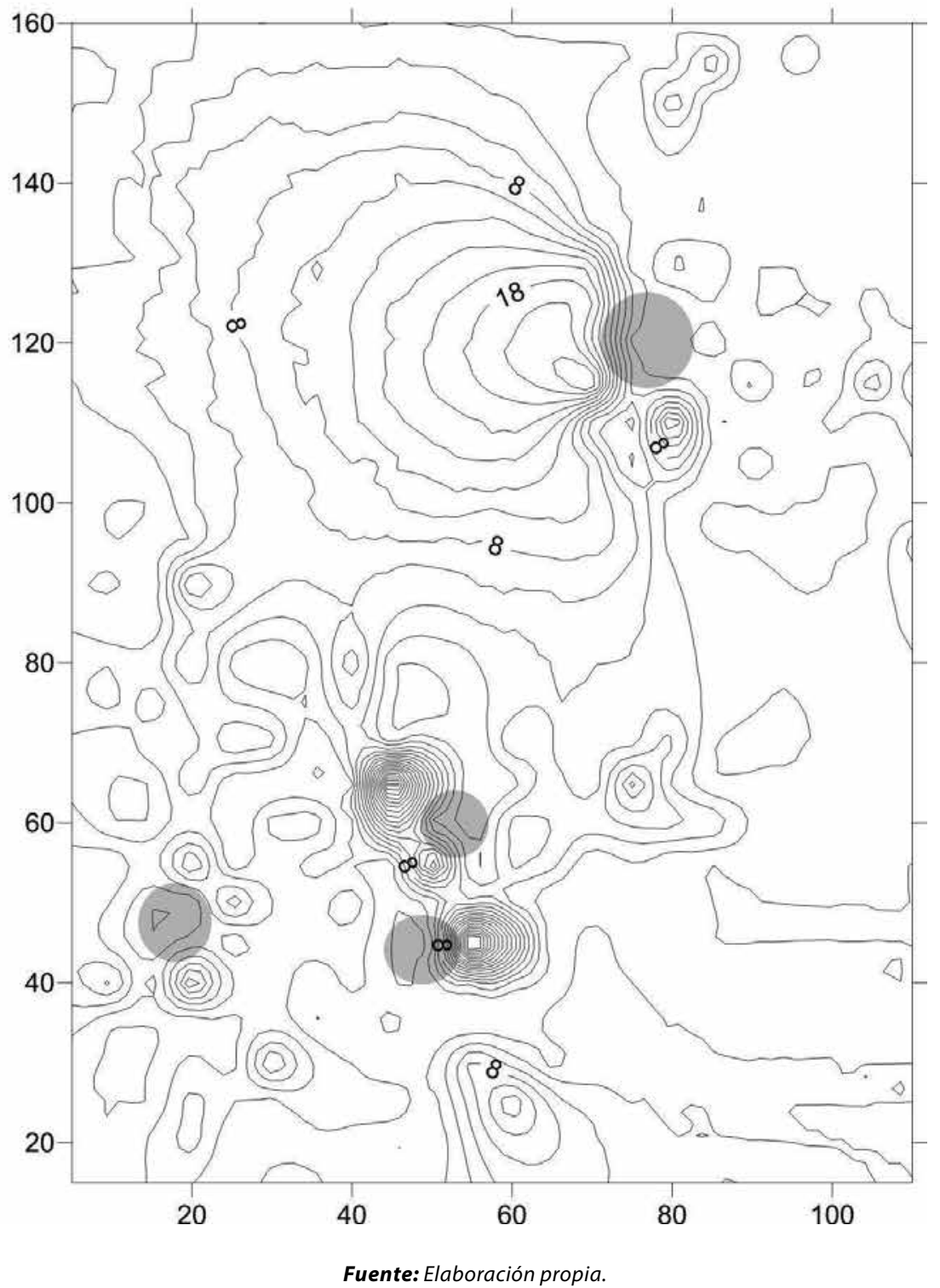

de la región por los españoles. A pesar de que la intención del autor al presentar las declaraciones de los nativos era demostrar la inexistencia de la institución de la jefatura, algunas de las afirmaciones no dejan duda sobre la práctica del tributo y, en consecuencia, de la institución cacical. Por las declaraciones, es indiscutible la presencia del trabajo excedente apropiado por los caciques en forma de 
tributo con productos y servicios, de índole forzosa, o maquillado como dádiva. Los cambis, grupo que moraba en la cuenca media del río La Plata, señalaron "que no han pagado tributo a los caciques los indios de este repartimiento. Y que cuando tienen maíz u otras cosas de comer lo dan al dicho cacique y por regalo”. Los mulales, comunidad que habitaba en las proximidades del actual municipio de San Agustín, dijeron "que cuando tenían cacique le daban estos indios de lo que tenían de cosas de comer, y esto era por presente y regalo no por vía de tributo”. Algunos laculatas, también habitantes de las cercanías de San Agustín, señalaron "que en tiempos antiguos hacían estos indios una rosa muy grande $a$ sus caciques en señal de tributo” (cit. en Friede 1974, 86-88, énfasis añadido).

La entrega de recursos del comunero al cacique, bajo la figura del regalo, no puede entenderse como benevolencia. A corto y largo plazo, esta práctica beneficiaba al cacique, porque, en esencia, se trataba de la preponderancia de su prestigio y liderazgo; era la apropiación, por ínfima que parezca, del trabajo del comunero.

Es bastante probable que las poblaciones nativas, poco después de la consolidación de la dominación española, advirtieran que las tasaciones dependían, en buena medida, de la existencia previa del tributo a los caciques. En consecuencia, aceptar la existencia de tal tributo implicaba tener que entregarlo a la Corona o a los encomenderos; por lo tanto, las afirmaciones más frecuentes en las visitas consistieron en negar su existencia.

El soldado Pero López, quien participó en la conquista de la región, en su crónica describe a Pigoanza como el cacique principal en el sur del Alto Magdalena, con bastante poder militar y abundantes recursos: "El rey Piguanza nos envió una carga de sal que en aquella tierra se tiene en más que oro y algunas cargas de turmas de tierra y frutas” ([1572 ¿?] 1970, 61). El avituallamiento debió ser abundante, pues, según el soldado-cronista, la hueste española estaba compuesta de 120 soldados. ¿Cómo disponer de tan abundantes recursos sin la existencia del tributo de los comuneros?

Otro aspecto de suma importancia, que se percibe durante la contienda militar con los españoles, tiene que ver con la conducta de algunos caciques; es un claro ejemplo cómo la sociedad no era un todo armónico, sino una entidad en permanente confrontación. No obstante la funcionalidad de la institución cacical y las estrategias para mantener la sujeción y la cohesión social con el propósito de garantizar la tributación a través de la generación de trabajo excedente, como formación social se hallaba escindida en grupos antagónicos: los comuneros, que producían los recursos indispensables, bienes y servicios, y la élite cacical, que controlaba los procesos de producción y el conjunto de la vida social. 
En anterior oportunidad (Sánchez 2007a) enfaticé que, en una sociedad estratificada de tipo cacical, ocurren en forma permanente diversos tipos de confrontaciones que son las que generan los cambios culturales. Una de las contradicciones importantes, aunque de tipo secundario, fue la que aconteció entre la élite regional dominante y los caciques secundarios, pues la posición de estos en la división del trabajo y, por ende, en las relaciones sociales era de subordinación económica y política al poder regional. La jerarquía usual en los cacicazgos complejos, como los imperantes durante el periodo Reciente, no implicaba compartir a plenitud la toma de decisiones ni los recursos extraídos a los comuneros. Por supuesto, los caciques secundarios disfrutaban de algunas prerrogativas económicas y políticas, pero solo estaban autorizados para tomar decisiones locales, ya que se hallaban subordinados a quienes realmente detentaban el poder regional, ámbito hacia donde fluían los recursos producidos en el ámbito local. Esto explica la actitud colaboracionista de caciques secundarios como Inando y Cameno, quienes informaban a los españoles sobre los movimientos de las huestes de Pigoanza y sus caciques allegados.

¿Por qué esta actitud en contra del poder regional que representaba Pigoanza? Es posible que los dos caciques rebeldes hicieran parte de, y encabezaran, segmentos que en algún momento fueron unidades políticas autónomas, luego sometidas a la entidad política regional que dirigía Pigoanza. O pudo tratarse de líderes de segmentos sociales a los que el sistema de parentesco relegó a la sujeción económica y política.

\section{Conclusiones}

A modo de balance, desde la perspectiva metodológica, resultan cuatro aspectos de suma importancia.

En primer lugar, en ninguna formación económico-social son posibles los procesos de producción puros; en el caso del territorio del actual municipio de Isnos, en épocas prehispánicas, coexistieron dos prácticas agrícolas diferentes que implicaban formas disímiles de organizar la producción, la disposición y magnitud de la fuerza de trabajo. De una parte, en el sector de La Marquesa, las condiciones adversas de los suelos requirieron una elevada inversión de fuerza de trabajo para excavar los canales de drenaje en los campos agrícolas, tarea que excedía la capacidad de una sola unidad doméstica, por lo que, seguramente, fue necesaria la participación de unidades vecinas, por lo menos durante la fase de 
excavación de los extensos sistemas de canales. En áreas aledañas, por el contrario, con suelos con mejores condiciones naturales, la producción agrícola era un asunto que, seguramente, ocupaba sobre todo a unidades domésticas individuales, pues no era necesario invertir mucha fuerza de trabajo en la adecuación de los suelos mediante obras de ingeniería. No obstante estas diferencias en los procesos de trabajo, en ambos casos, las condiciones dominantes de la producción fueron tributarias. Con todo, no se necesitó de agentes políticos encargados del diseño y la dirección de la construcción de los sistemas de canales para drenaje (los trazados difieren de una colina a otra) (Sánchez 2005, 14-16), sino que se trató de obras que comprometieron el trabajo de las unidades domésticas que ocupaban la colina en cuestión y, tal vez, de unidades vecinas.

En segundo lugar, es claro que la forma que asumió la apropiación de una porción del trabajo de los comuneros por parte de la cúpula cacical cambió de acuerdo con el grado de confrontación social en los procesos de producción. Por esta razón, variaban las justificaciones y los mecanismos mediante los cuales se buscaba extraer beneficios con el propósito de reproducir la estructura social, justificaciones y artilugios que generalmente disfrazaban la realidad. A propósito, señala Balandier que el poder no se mantiene mediante la coerción ni la racionalidad, sino "por la trasposición, por la producción de imágenes, por la manipulación de símbolos y su ordenamiento en un cuadro ceremonial” $(1994,18)$, es decir, las justificaciones y mecanismos puestos en escena son artilugios que, como arqueólogos, estamos obligados a identificar y desenmascarar para lograr explicaciones coherentes que realmente sean pertinentes y útiles a la sociedad del presente.

En tercer lugar, pese a la importancia capital de la división social del trabajo determinada por las relaciones sociales, e incluso a pesar del peso decisorio de la organización política, algunos eventos naturales, en este caso la calidad de los suelos y los cambios climáticos adversos, también pueden haber influido radicalmente en la modalidad de la participación social en los procesos productivos.

Finalmente, resulta claro que la magnitud tanto del trabajo necesario como del trabajo excedente y su apropiación eran asuntos determinados socialmente, y que para hacerlos posibles se contaba con diversos mecanismos culturales y políticos. Así que, por lo menos durante el periodo Clásico Regional, el mecanismo fundamental consistió en la celebración de rituales de índole funeraria. Evidentemente, el mecanismo fue diferente durante el periodo Reciente, cuando, según las declaraciones tardías transcritas por Friede, consistió en la obligatoriedad o la dádiva, aunque no tenemos claro cuál fue la forma dominante. 


\section{Referencias}

Balandier, Georges. 1994. El poder en escenas. De la representación del poder al poder de la representación. Barcelona: Paidós.

Carneiro, Robert L. 1970. "A Theory of the Origin of the State”. Science 169: 733-738.

—. 1988. "The Circumscription Theory. Challenge and Response". American Behavioral Scientist 31: 497-511.

Drennan, Robert D. 1985. Arqueología regional en el valle de La Plata, Colombia. Informe preliminar sobre la temporada de 1984 del Proyecto Arqueológico Valle de La Plata. Michigan: Museum of Anthropology, University of Michigan.

-.2000. Las sociedades prehispánicas del Alto Magdalena. Bogotá: Instituto Colombiano de Antropología e Historia.

Drennan, Robert D. et al. 1989. "El medioambiente y la ocupación humana”. En El contexto medioambiental de la ocupación humana, t. 1 de Cacicazgos prehispánicos del valle de La Plata, editado por Luisa Fernanda Herrera, Robert D. Drennan y Carlos A. Uribe, 226-232. Pittsburgh; Bogotá: University of Pittsburgh, Department of Anthropology; Universidad de los Andes, Departamento de Antropología.

Drennan, Robert D. et al. 2006. Patrones de asentamiento regionales. T. 5 de Cacicazgos prehispánicos del valle de La Plata. Pittsburgh; Bogotá: University of Pittsburgh, Department of Anthropology; Universidad de Los Andes, Departamento de Antropología.

\section{Drennan, Robert D., Víctor González y} Carlos A. Sánchez. En prensa. Regional Settlement Patterns in the Alto Magdalena: The San Agustín-Isnos/Patrones de asentamiento regionales en el Alto Magdalena: la zona San Agustín-Isnos.
University of Pittsburgh Memoirs in Latin American Archaeology.

Duque Gómez, Luis. 1964. Exploraciones arqueológicas en San Agustín. Bogotá: Ministerio de Educación Nacional; Instituto Colombiano de Antropología.

Duque Gómez, Luis y Julio César Cubillos. 1988. Arqueología de San Agustín. Alto de Lavapatas. Bogotá: Fundación de Investigaciones Arqueológicas Nacionales, Banco de la República.

Friede, Juan. 1974. Los andakí. 1538-1947. Historia de la aculturación de una tribu selvática. México: Fondo de Cultura Económica.

Godelier, Maurice. 2000. Cuerpo, parentesco y poder. Perspectivas antropológicas y críticas. Quito: Abya-Yala.

Lee, Richard B. 1990. "Primitive Communism and the Origin of Social Inequality". En Upham 1990, 225-246.

López, Pero. (1572 ¿?) 1970. Pero López. Rutas de Cartagena de Indias a Buenos Aires y sublevaciones de Pizarro, Castilla y Hernández Girón. 1540-1570. Transcripción y anotaciones de Juan Friede. Madrid: Atlas.

Marx, Karl. (1875) 1971. Crítica del programa de Gotha. Beijing: Ediciones en Lenguas Extranjeras.

Meillassoux, Claude. 1977. Mujeres, graneros y capitales. México: Siglo Veintiuno.

Quattrin, Dale W. 2001. Economía vertical, intercambio y cambio social durante el periodo Formativo. T. 4 de Cacicazgos prehispánicos del valle de La Plata. Pittsburgh; Bogotá: University of Pittsburgh, Department of Anthropology; Universidad de los Andes, Departamento de Antropología.

Saitta, Dean J. 1994. "Class and Community in the Prehistoric Southwest”. En The Ancient Southwestern Community. Models 
and Methods for the Study of Prehistoric Social Organization, editado por W. H. Will y R. D. Leonard, 25-43. Albuquerque: University of New Mexico Press.

Saitta, Dean J. y Arthur Keene. 1990.

"Politics and Surplus Flow". En Upham 1990, 203-224.

Sánchez, Carlos Augusto. 2000. "Agricultura intensiva, dinámica de población y acceso diferencial a la tierra en el Alto Magdalena”. Arqueología del Área Intermedia 2: 69-98.

—. 2005. "Constricción social y estrategias productivas agrícolas prehispánicas en el Alto Magdalena”. Maguaré 19: 125-156.
-. 2007a. Economía y sociedad prehispánica. El uso de la tierra en el Alto Magdalena. Bogotá: Fundación de Investigaciones Arqueológicas Nacionales, Banco de la República.

-. 2007b. "El individuo: singularidad cultural y desarrollo social. Una mirada desde la arqueología”. Maguaré 21: 161-188.

Upham, Steadman, ed. 1990. The Evolution of Political Systems. Sociopolitics in Small-Scale Sedentary Societies. Cambridge: Cambridge University Press. 